\title{
Decrease in Cation Exchange Capacity of Zeolites at Neutral pH: Examples and Proposals of a Determination Method
}

\author{
Moses Wazingwa Munthali, Ponyadira Kabwadza-Corner, Erni Johan, Naoto Matsue \\ Laboratory of Applied Chemistry for Environmental Industry, Faculty of Agriculture, Ehime University, \\ Matsuyama, Japan \\ Email: munthalimw@yahoo.co.uk
}

Received 26 May 2014; revised 20 June 2014; accepted 18 July 2014

Copyright (C) 2014 by authors and Scientific Research Publishing Inc.

This work is licensed under the Creative Commons Attribution International License (CC BY). http://creativecommons.org/licenses/by/4.0/

c) (i) Open Access

\begin{abstract}
Cation exchange capacity (CEC) is an important characteristic of zeolites, especially when they are used as adsorbents in the aqueous system. However, no international standard method exists for the determination of CEC of zeolites. We determined CEC of Linde-type A and Na-P1 type zeolites at various $\mathrm{pH}$ (4 to 10) with a simple method, where $\mathrm{Na}^{+}$-saturated zeolites were prepared, and then various amounts of $\mathrm{HCl}$ were added. CEC was simply calculated by subtracting the amount of $\mathrm{Na}^{+}$in the final supernatant from the content of $\mathrm{Na}^{+}$of the $\mathrm{Na}^{+}$-saturated zeolites. CEC of the zeolites decreased with decreasing $\mathrm{pH}$ and with decreasing $\mathrm{Na}^{+}$concentration of the final supernatant. The concentration of $\mathrm{Na}^{+}$of the supernatant, CEC of the zeolites began to decrease at weakly alkaline or neutral $\mathrm{pH}$, and that of the Linde-type A zeolite became about half at $\mathrm{pH}$ around 6. When CEC was plotted against $\mathrm{pH}-\mathrm{pNa}$; where pNa is negative logarithm of the activity of $\mathrm{Na}^{+}$; $\mathrm{CEC}$ of each zeolite was expressed by a curve. It indicates that the CEC or the amount of $\mathrm{Na}^{+}$retention is univocally determined by the ratio of activities of $\mathrm{Na}^{+}$and proton.
\end{abstract}

\section{Keywords}

Cation Exchange Capacity, $\mathrm{Na}^{+}$Retention, pH Dependence, Linde-Type A Zeolite, Na-P1 Type Zeolite

\section{Introduction}

Various zeolite species have been utilized as adsorbents and catalysts usually in gases and organic solvents. Zeolites are also used in aqueous system to adsorb cations such as heavy metals and radioactive cesium, by uti- 
lizing their high negative charge density and high selectivity toward some kinds of cations [1] [2]. When zeolites are used as adsorbent in aqueous system, cation exchange capacity (CEC) of zeolites is one of the important factors to estimate their ability, but no international standard method is available for the determination of CEC of zeolites. A possible reason for this is that CEC of zeolites have been considered to be same as the amount of isomorphous substitution. On one hand, CEC of soil clay minerals in aqueous system had been extensively studied with agricultural purposes: in this case, "cation” meant cations except for proton. Consequently, two types of negative charges, namely $\mathrm{pH}$-dependent and $\mathrm{pH}$-independent negative charges had been recognized in soil clay minerals [3]. The pH-dependent negative charge is due to the dissociation of $\mathrm{Si}-\mathrm{OH}, \mathrm{Al}-\mathrm{OH}$ and $\mathrm{Fe}-\mathrm{OH}$ groups of soil clays, and the $\mathrm{pH}$-independent negative charge was ascribed to 2:1 type layer silicate clay minerals such as montmorillonite. Because origin of the negative charge of the 2:1 type layer silicate clay minerals is isomorphous substitution, negative charges derived from isomorphous substitution, including those of zeolites, had been thought to be independent of $\mathrm{pH}$, at least under environmental $\mathrm{pH}$ of about 4 - 10 [4]. Some studies were carried out concerning $\mathrm{pH}$-dependent adsorption of $\mathrm{Ca}^{2+}[5], \mathrm{Pb}^{2+}$ [6], sulfa drugs [7], and phenol [8] on zeolites from acidic to alkaline $\mathrm{pH}$ range. However, detailed cation retention behavior of various zeolite species as affected by $\mathrm{pH}$ is not known, especially at neutral $\mathrm{pH}$ region. In this study, we found that the CEC (the amount of $\mathrm{Na}^{+}$retention) of Linde-type A and Na-P1 type zeolites decreased with decreasing $\mathrm{pH}$, and the decrease began at $\mathrm{pH}$ around 7 to 9 . We also proposed a simple method to determine the effect of $\mathrm{pH}$ and cation activity on the CEC of zeolites.

\section{Materials and Methods}

\subsection{Sample Preparation}

Two zeolite species were used in this study. Linde-type A zeolite was obtained from Wako Chemicals Ltd, and Na-P1 type zeolite was synthesized in this study. Linde-type A zeolite is a common zeolite species, and Na-P1 type zeolite is a main zeolite species when low price "artificial zeolite" is synthesized from coal fly ash. In a 250 $\mathrm{mL}$ centrifuge bottle, $10 \mathrm{~g}$ of the zeolite was washed five times with $150 \mathrm{~mL}$ of $1 \mathrm{M} \mathrm{NaCl}$ to saturate the zeolite with $\mathrm{Na}^{+}$. Then the content was washed twice with $150 \mathrm{~mL}$ of water, washed once with $100 \mathrm{~mL}$ of acetone, airdried, and used as a sample.

\subsection{Determination of CEC}

The $\mathrm{Na}^{+}$contained in the sample are retained exchangeable $\mathrm{Na}^{+}$and free $\mathrm{Na}^{+}$as $\mathrm{NaCl}$. The sum of retained and free $\mathrm{Na}^{+}$contents of the sample (hereafter $\mathrm{Na}^{+}$content) was determined by washing $1 \mathrm{~g}$ of the sample with 30 $\mathrm{mL}$ of $1 \mathrm{M} \mathrm{NH}_{4} \mathrm{NO}_{3}$ in a $50 \mathrm{~mL}$ centrifuge bottle for seven times. Water content of the sample was determined by heating at $105^{\circ} \mathrm{C}$ for $3 \mathrm{~h}$. The content of $\mathrm{Si}$ and $\mathrm{Al}$ of the samples was determined after dissolution with hydrofluoric acid. The determination of CEC (the amount of $\mathrm{Na}^{+}$retention) of the samples was carried out with the following method, which was modified from a method proposed for soil clays [9]. One gram of a sample was put in a $250 \mathrm{~mL}$ centrifuge bottle, and $200 \mathrm{~mL}$ of 0 to $7.5 \mathrm{mM} \mathrm{HCl}$ solution was added. The mixture was shaken for $3 \mathrm{~h}$ at $25^{\circ} \mathrm{C} \pm 0.5^{\circ} \mathrm{C}$, centrifuged at $2000 \mathrm{~g}$, and the concentration of $\mathrm{Na}^{+}$and $\mathrm{pH}$ of the supernatant were measured. Preliminary experiments indicated that the $\mathrm{Na}^{+}$concentration and $\mathrm{pH}$ of the supernatant became constant within $3 \mathrm{~h}$, and the measured $\mathrm{Na}^{+}$concentration and $\mathrm{pH}$ are hereafter referred to as equilibrium $\mathrm{Na}^{+}$concentration and equilibrium $\mathrm{pH}$, respectively. The CEC (the amount of $\mathrm{Na}^{+}$retention) of the sample was simply calculated from the difference between $\mathrm{Na}^{+}$content of the sample and the amount of $\mathrm{Na}^{+}$in the supernatant. Similar CEC determination as the above was carried out using $50 \mathrm{~mL}$ centrifuge bottle, $1 \mathrm{~g}$ of sample, $20 \mathrm{~mL}$ of solutions containing of 0 to $75 \mathrm{mM} \mathrm{HCl}$ and $83 \mathrm{mM} \mathrm{NaCl}$, to estimate the effect of solution $\mathrm{Na}^{+}$concentration on CEC at a same equilibrium $\mathrm{pH}$. The volume of $20 \mathrm{ml}$ was used in order to increase the relative change of $\mathrm{Na}^{+}$ concentration in the supernatant, and to increase the accuracy of $\mathrm{Na}^{+}$concentration determination. The concentration of $\mathrm{Al}$ and $\mathrm{Si}$ in the supernatant was measured to check the dissolution of the sample, and the measurement of $\mathrm{Na}, \mathrm{Al}$ and $\mathrm{Si}$ was carried out using atomic absorption spectrophotometer (Hitachi Z-5000).

Powder X-ray diffraction pattern of the samples before and after the CEC determination was obtained with a Rigaku Ultima IV X-ray diffractometer with $\mathrm{Cu}-\mathrm{K} \alpha$ radiation generated at $40 \mathrm{kV}$ and $40 \mathrm{~mA}$, between $3^{\circ}-60^{\circ}$ of $2 \theta$ angles with a sampling width of $0.02^{\circ}$ and a scanning rate of $2^{\circ} \cdot \min ^{-1}$. 


\section{Results and Discussions}

Figure 1 shows change in CEC (the amount of $\mathrm{Na}^{+}$retention, $\mathrm{cmol} \cdot \mathrm{kg}^{-1}, 105^{\circ} \mathrm{C}$ oven dry basis) of the zeolite samples with change of equilibrium pH. Closed symbols in Figure 1 show the results without NaCl background solution in total volume of $200 \mathrm{~mL}$, and open symbols are the results with $83 \mathrm{mM} \mathrm{NaCl}$ in $20 \mathrm{~mL}$. In the absence of $\mathrm{NaCl}$, the concentrations of $\mathrm{Na}^{+}$in the supernatants were from $0.3 \mathrm{mM}$ to $7.4 \mathrm{mM}$ for Linde-type A zeolite, and $0.1 \mathrm{mM}$ to $6.6 \mathrm{mM}$ for Na-P1 type zeolite, with increasing the amount of addition of $\mathrm{HCl}$. When 83 $\mathrm{mM} \mathrm{NaCl}$ was added, they were $88 \mathrm{mM}$ to $153 \mathrm{mM}$ for Linde-type A zeolite, and $85 \mathrm{mM}$ to $138 \mathrm{mM}$ for Na-P1 type zeolite.

In the absence of the $\mathrm{NaCl}$ background solution (closed symbols in Figure 1), at higher $\mathrm{pH}$ region, $\mathrm{CEC}$ of the two samples were slightly affected by $\mathrm{pH}$. With increasing the amount of $\mathrm{HCl}$ addition, equilibrium $\mathrm{pH}$ decreased, and CEC of the two zeolites decreased with the decrease of the equilibrium pH. The CEC of Na-P1 type zeolite began to decrease from $\mathrm{pH}$ about 7 (Figure 1, closed triangles), and that of Linde-type A zeolite began to decrease from $\mathrm{pH}$ about 9 (Figure 1, closed circles). The decrease of CEC indicates that the negative charge of zeolite was partly compensated by the adsorption of proton with the exchange with $\mathrm{Na}^{+}$. The adsorption of proton onto the zeolites is due to greater selectivity of the zeolites toward proton, and Figure 1 reveals that the adsorption of proton on the two zeolites occurred even at neutral pH region. In other words, CEC of the two zeolites is $\mathrm{pH}$-dependent, and the zeolites are strong base like $\mathrm{Si}-\mathrm{O}^{-}$of $\mathrm{Si}-\mathrm{OH}$ group. Decrease in the retention of cations by zeolites with decrease in $\mathrm{pH}$ were also reported for $\mathrm{Ca}^{2+}$ on Linde-type $\mathrm{A}$ zeolite [5], and for $\mathrm{Pb}^{2+}$ on NKF-6 zeolite [6].

When $83 \mathrm{mM} \mathrm{NaCl}$ was added as a background solution (open symbols in Figure 1), CEC of the samples began to decrease from around $\mathrm{pH} 6$ for Na-P1 type zeolite, and from around $\mathrm{pH} 8$ for Linde-type A zeolite. As a result, at a same equilibrium $\mathrm{pH}$ in Figure 1, CEC of open symbols were greater than those of closed symbols, and the difference was greater at lower equilibrium $\mathrm{pH}$. This means that not only $\mathrm{pH}$, but also $\mathrm{Na}^{+}$concentration (more accurately, activity of $\mathrm{Na}^{+}$) affected CEC or the amount of $\mathrm{Na}^{+}$retention of the zeolites. The effect of a monovalent cation $\left(\mathrm{M}^{+}\right)$concentration on CEC was already reported for soils and soil clay minerals, and the effect of both $\mathrm{pH}$ and $\mathrm{M}^{+}$concentration was expressed by taking the abscissa as $\mathrm{pH}-\mathrm{pM}$ or $\log \left\{\left(\mathrm{M}^{+}\right) /\left(\mathrm{H}^{+}\right)\right\}$ [10].

Then we re-plotted the data in Figure 1 by taking the abscissa as pH-pNa, as shown in Figure 2. The figure shows that closed symbols and open symbols are nearly converged to a curve in both types of zeolites. This indicates that, in these experimental systems, CEC (the amount of $\mathrm{Na}^{+}$retention) is univocally determined by the ratio of activities of $\mathrm{Na}^{+}$and proton, similar to the case of soils and soil clay minerals [10]. Figure 2 also indicates that the determination of $\mathrm{CEC}$ with the addition of $\mathrm{NaCl}$ in the $\mathrm{HCl}$ solution is not necessary. By plotting CEC against $\mathrm{pH}-\mathrm{pNa}$ using the results with simple $\mathrm{HCl}$ solutions, $\mathrm{CEC}$ at a $\mathrm{pH}$ with higher $\mathrm{Na}^{+}$concentration is easily obtained. Here, $\mathrm{Na}^{+}$in aqueous solution is in hydrated form and weakly held or adsorbed onto zeolites [11]. In this case, the adsorption of proton on zeolite is more preferred than $\mathrm{Na}^{+}$. Furthermore, specific Brönsted and Lewis acid-base sites exist in zeolite micropores [12] [13]. Considering the Lewis acid-base sites, after a proton is adsorbed through ion exchange with $\mathrm{Na}^{+}$, the proton acts as a Lewis acid while the O between Si-O-Al acts as a Lewis base. Then the $\mathrm{O}$ gives lone pair electrons to the proton which results into a negative charge neutralization due to the formation of covalent bonding between the $\mathrm{O}$ and the proton [14]. The formed covalent bonding results into neutral charge and a loss of negative charge in zeolite. The covalent bonding is much stronger than the ionic bonding formed by $\mathrm{Na}^{+}$cation in balancing up the negative charge. The addition of $\mathrm{HCl}$ was from 0 to $150 \mathrm{cmol}$ for $1 \mathrm{~kg}$ of zeolite. Within this range, the change in XRD pattern was not observed as shown in Figure 3, and the amount of dissolution of Si and $\mathrm{Al}$ was less than $0.5 \%$ and $0.1 \%$, respectively. With more addition of $\mathrm{HCl}$, it is clear that the zeolites are dissolved. When zeolites are used in aqueous systems, the dissolution of the zeolites should be taken into account.

In this study, two types of zeolites were used, and $\mathrm{Na}^{+}$was used as an index cation for the determination of CEC. In addition to $\mathrm{pH}$ and the activity of an index cation, CEC of a zeolite may change with index cation species and the amounts and species of coexistent ions. However, CEC data obtained with the method used in this study will give the basic information for the prediction of cation retention and solubility of a zeolite in more complicated aqueous systems.

\section{Conclusion}

In conclusion, CEC of Linde-type and Na-P1 type zeolites was strongly pH dependent even at weakly acidic 


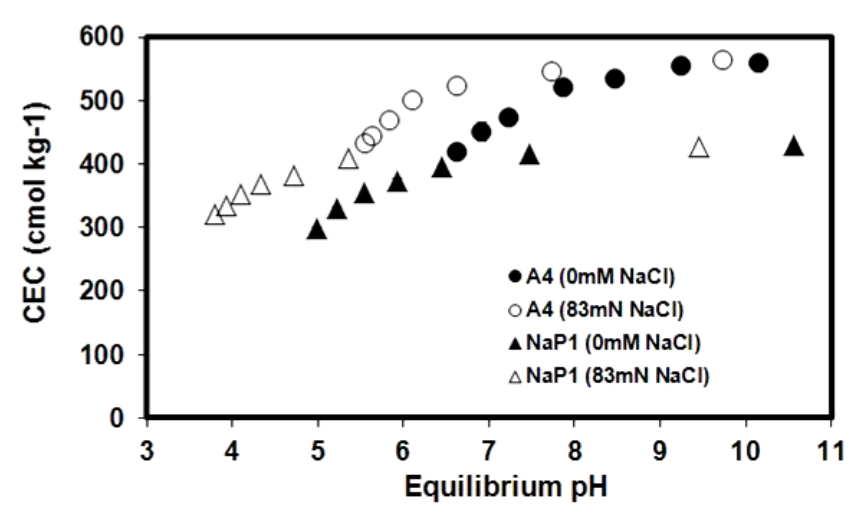

Figure 1. Changes in CEC of zeolites with equilibrium pH. Note: Linde-type A $=4 \mathrm{~A}$.

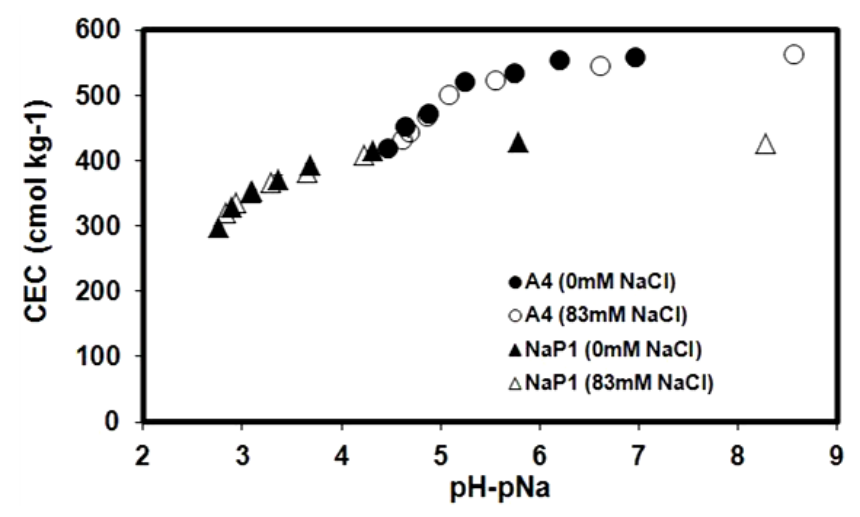

Figure 2. Changes in CEC of zeolites with pH-pNa. Note: Lindetype $\mathrm{A}=4 \mathrm{~A}$.
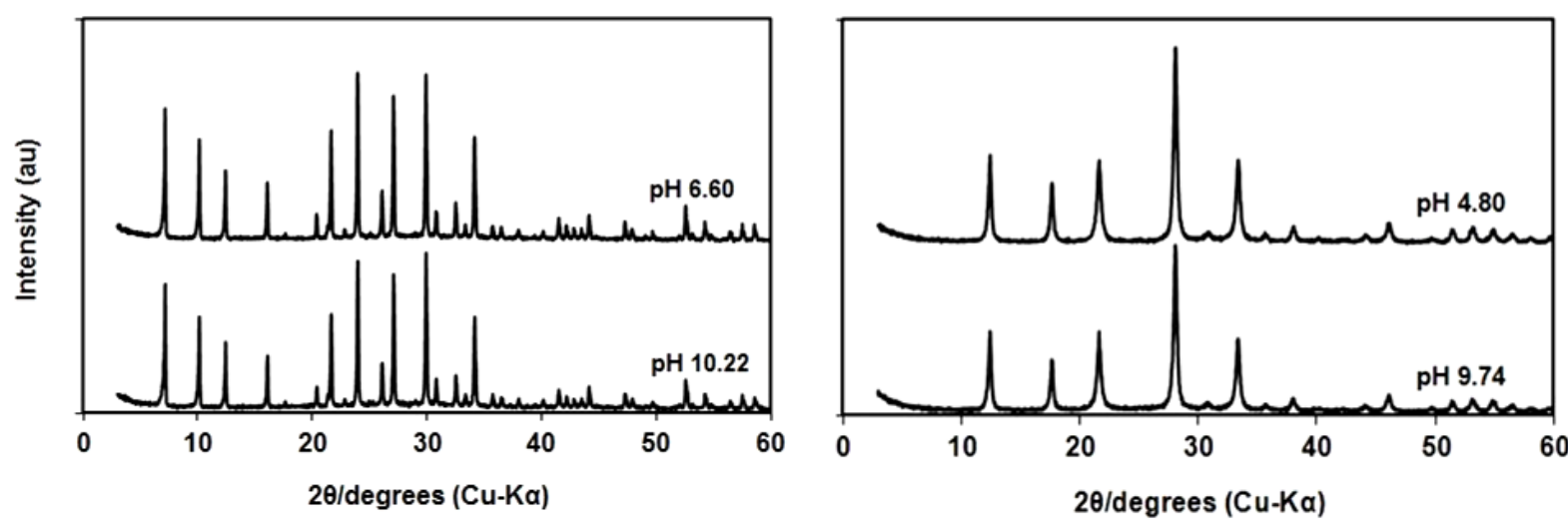

Figure 3. XRD patterns of Linde-type A zeolite (left) and Na-P1 zeolite (right) after CEC measurement without NaCl addition. $\mathrm{pH}$ values on each $\mathrm{XRD}$ pattern indicate equilibrium $\mathrm{pH}$.

range. CEC of the zeolites was also affected by the activity of $\mathrm{Na}^{+}$in solution, and CEC was well expressed by pH-pNa. The method used in this study for the determination of CEC at various $\mathrm{pH}$ is simple, with minimal sample destruction. Outline of a method for the determination of CEC at various pH is proposed as follows: 1) Prepare air-dried $\mathrm{Na}^{+}$-saturated sample, and contents of water and $\mathrm{Na}^{+}$are measured; 2) To $1 \mathrm{~g}$ of the sample, $200 \mathrm{~mL}$ of 0 to $7.5 \mathrm{mM} \mathrm{HCl}$ are added; 3) Shake for $3 \mathrm{~h}$, centrifuge, and $\mathrm{pH}$ and $\mathrm{Na}^{+}$concentration of supernatant are measured; 4) Calculate CEC by subtracting the amount of $\mathrm{Na}^{+}$in the supernatant from $\mathrm{Na}^{+}$content of the sample; 5) Calculate activity of $\mathrm{Na}^{+}$for each supernatant, and plot CEC against pH-pNa. By adding known amount of $\mathrm{NaOH}$, instead of $\mathrm{HCl}$, CEC at higher $\mathrm{pH}$-pNa is also obtained. 


\section{References}

[1] Misaelides, P. (2011) Application of Natural Zeolites in Environmental Remediation: A Short Review. Microporous and Mesoporous Materials, 144, 15-18. http://dx.doi.org/10.1016/j.micromeso.2011.03.024

[2] Wang, S. and Peng, Y. (2010) Natural Zeolites as Effective Adsorbents in Water and Wastewater Treatment. Chemical Engineering Journal, 156, 11-24. http://dx.doi.org/10.1016/j.cej.2009.10.029

[3] McBride, M.B. (1989) Surface Chemistry of Soil Minerals. In: Dixon, J.B. and Weed, S.B., Eds., Minerals in Soil Environments, 2nd Edition, SSSA Book Series No. 1, Soil Science Society of America, Madison, 35-88.

[4] Ferreiro, E.A., Helmy, A.K. and de Bussetti, S.G. (1995) Interaction of Fe-Oxyhydroxide Colloidal Particles with Montmorillonite. Clay Minerals, 30, 195-200. http://dx.doi.org/10.1180/claymin.1995.030.3.03

[5] Qin, C., Wang, R. and Ma, W. (2010) Characteristic of Calcium Adsorption by Ca-Selectivity Zeolite in Fixed-pH and in a Range of pH. Chemical Engineering Journal, 156, 540-545. http://dx.doi.org/10.1016/j.cej.2009.04.006

[6] Yang, X., Yang, S., Yang, S., Hu, J., Tan, X. and Wng, X. (2011) Effect of pH, Ionic Strength and Temperature on Sorption of $\mathrm{Pb}(\mathrm{II})$ on NKF-6 Zeolite Studied by Batch Technique. Chemical Engineering Journal, 168, 86-93. http://dx.doi.org/10.1016/j.cej.2010.12.039

[7] Fukahori, S., Fujiwara, T., Ito, R. and Funamizu, N. (2011) pH-Dependent Adsorption of Sulfa Drugs on High Silica Zeolite: Modelling and Kinetic Study. Desalination, 275, 237-242. http://dx.doi.org/10.1016/j.desal.2011.03.006

[8] Yousef, R. and El-Eswed, B. (2009) The Effect of pH on the Adsorption of Phenol and Chlorophenols onto Natural Zeolite. Colloids and Surfaces A: Physicochemical and Engineering Aspects, 334, 92-99. http://dx.doi.org/10.1016/j.colsurfa.2008.10.004

[9] Wada, S. (1983) pH- and Ionic Concentration-Dependence of Monovalent Cation Retention by Clays and Clay Minerals Expected in Soils. Soil Science and Plant Nutrition, 29, 561-564. http://dx.doi.org/10.1080/00380768.1983.10434660

[10] Wada, S. and Kawabata, K. (1991) Ion Adsorption on Variable Charge Materials and Thermodynamics of Ion Exchange. Soil Science Plant Nutrition, 37, 191-200. http://dx.doi.org/10.1080/00380768.1983.10434660

[11] Deka, R.C., Roy, R.K. and Hirao, K. (2004) Local Reactivity Descriptors to Predict the Strength of Lewis Acid Sites in Alkali Cation-Exchanged Zeolites. Chemical Physics Letters, 389, 186-190. http://dx.doi.org/10.1016/j.cplett.2004.03.094

[12] Almutairi, M.T., Mezari, B., Filonenko, A., Magusin, P.C.M.M., Rigutto, M.S., Pidko, E.A. and Hensen, E.J.M. (2013) Influence of Extraframework Aluminum on the Brønsted Acidity and Catalytic Reactivity of Faujasite Zeolite. ChemCatChem, 5, 452-456.

[13] Serykh, A.I. (2005) Nature of Cadmium Cationic Sites in Cadmium-Modified ZSM-5 Zeolite According to the Drift Studies of Molecular Hydrogen Adsorption. Microporous and Mesoporous Material, 80, 321-326. http://dx.doi.org/10.1016/j.micromeso.2004.10.024

[14] Malik, A.S., Boyko, O., Aktar, N. and Young, W.F. (2009) A Comparative Study of MR Imaging Profile of Titanium Pedicle Screws. Acta Radiologica, 42, 291-293. http://dx.doi.org/10.1080/028418501127346846 
Scientific Research Publishing (SCIRP) is one of the largest Open Access journal publishers. It is currently publishing more than 200 open access, online, peer-reviewed journals covering a wide range of academic disciplines. SCIRP serves the worldwide academic communities and contributes to the progress and application of science with its publication.

Other selected journals from SCIRP are listed as below. Submit your manuscript to us via either submit@scirp.org or Online Submission Portal.
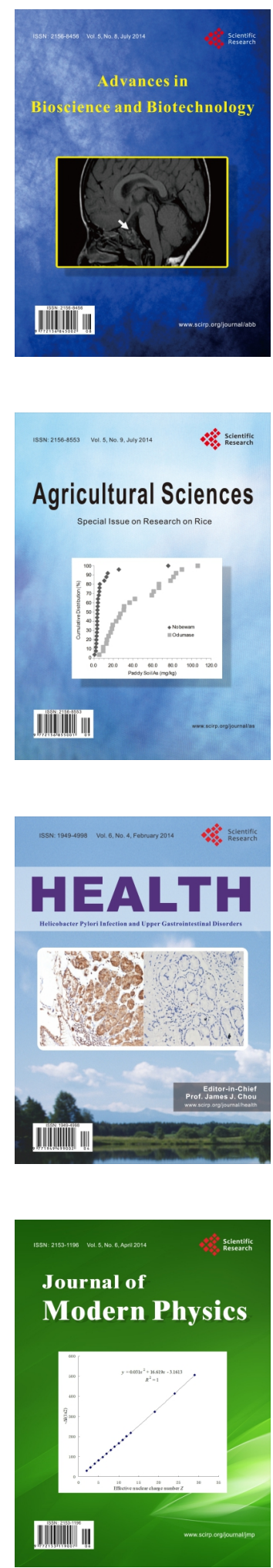
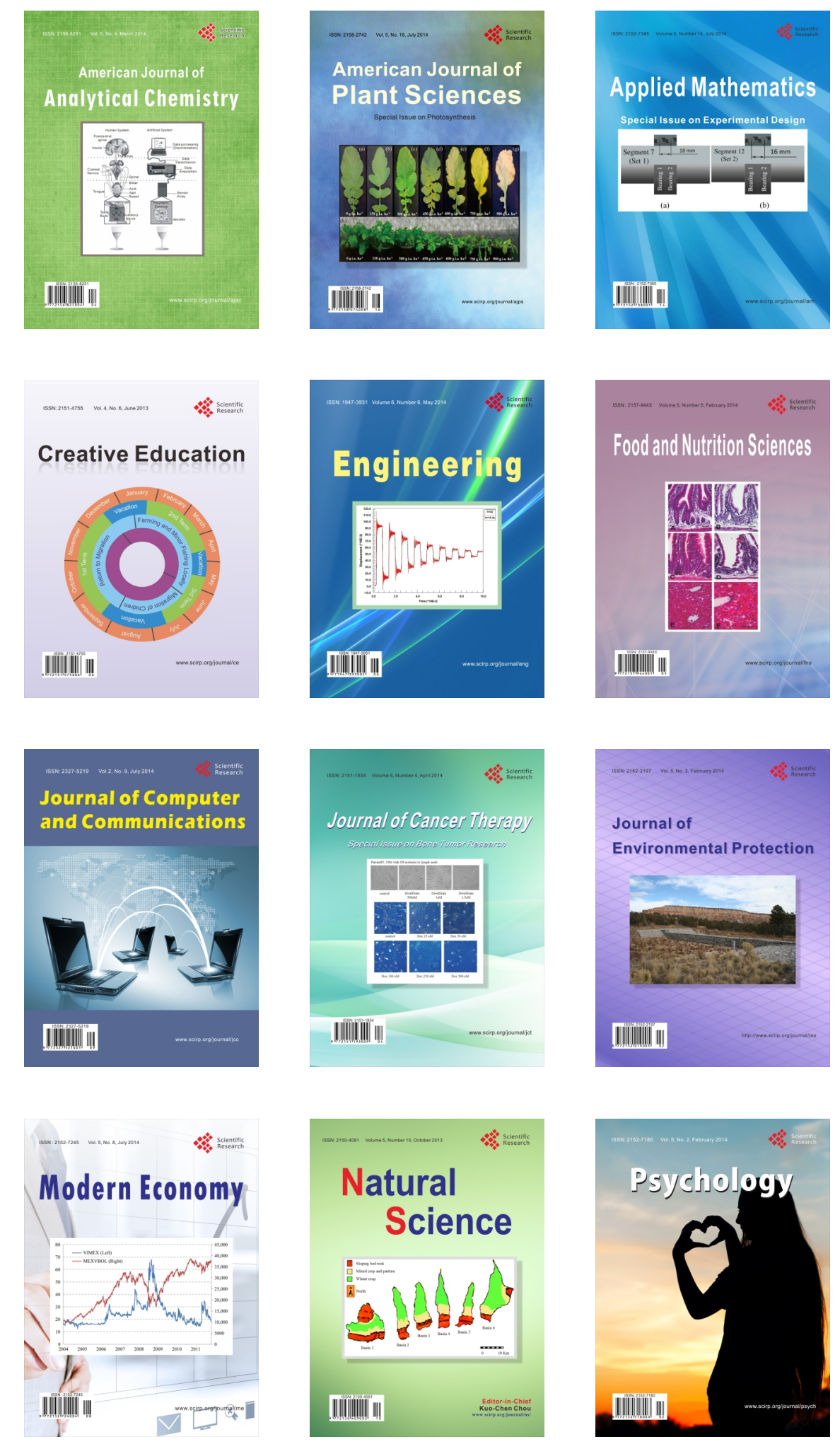